\title{
Gobernanza urbana y metropolitana en el accionar público contemporáneo
}

\author{
Urban and metropolitan governance in the \\ actioning contemporary public
}

Andrés Medina-Garzón ${ }^{1}$

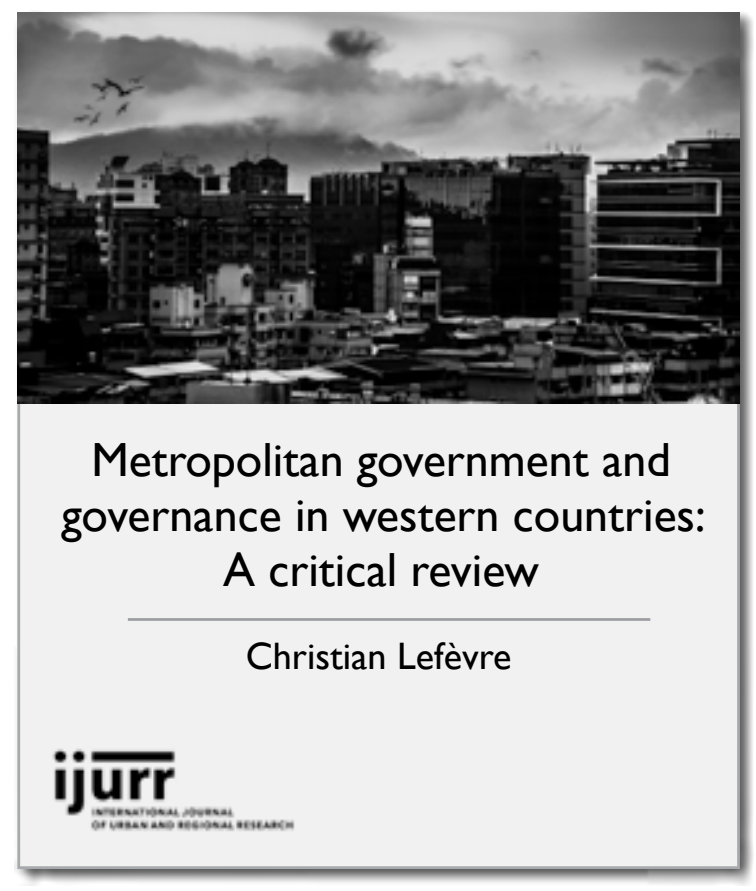

Reseña analítica de

Metropolitan Government and Governance in Western Countries: A Critical Review

Christian Lefèvre, 1998.

International Journal of Urban and Regional

Research, Vol. 22 Issue 1, pp. 9-25.

\footnotetext{
${ }^{1}$ Arquitecto de la Pontificia Universidad Javeriana, Especialista en Gestión Regional del Desarrollo del Centro Interdisciplinario de Estudios sobre Desarrollo CIDER de la Universidad de los Andes. Actualmente, estudiante de la Maestría en Planificación Urbana y Regional, consultor independiente y asistente de investigación en Desarrollo Económico Local, Competitividad e Innovación territorial del mismo centro de estudios.

Correo electrónico:

am.medinag@uniandes.edu.co.

0000-0002-8185-4889
}

En la esfera pública de los últimos 50 años, varios han sido los factores que han dado pie para que la discusión del concepto del gobierno metropolitano, entre ellos, la integración europea, la globalización, la promulgación de las nuevas tecnologías y las crisis financieras desde la década del setenta. Ello ha implicado el reconocimiento de diferentes dinámicas y actores de la sociedad, para lo que el autor deja en evidencia que, para él, la Gobernanza es entendida como las nuevas formas del accionar público: "resulta del proceso que trae al juego la buena gobernanza logrando consensos sociales y llegando a objetivos comunes" (Lefèvre, 1998, p. 9).

En términos generales, el gobierno metropolitano favorece la idea de la nueva institucionalidad basándose en la legitimidad política, el otorgamiento de autonomía a diferentes escalas de poder, el amplio rango jurisdiccional y la gran comprensión (extensión) territorial. Fue en la década del sesenta, cuando varios autores empezaron a dar soporte y apoyo a lo que se llamó el modelo metropolitano; como consigna básica, argumentaban que las grandes estructuras resultaban más democráticas, ya que "la participación política aumentaba en relación con el poder del gobierno local" (Sharpe, 1995, citado en Lefèvre, 1998, p. 10). Así mismo, consideraban que la 'diferenciación' o segregación institucional solo lograba dispersar las actividades y no se desarrollaba el máximo potencial de la región. 
De manera paralela, quienes apoyaban la corriente de la elección pública, apelaban a la posibilidad de aprovechar el potencial de las estructuras existentes sin la necesidad de crear grandes maquinarias de poder. En adición, criticaban el distanciamiento entre las autoridades y los ciudadanos, como la monopolización del poder público por parte de las instituciones; defendían la fragmentación institucional en orden de mantener la competitividad. De igual forma, desconocían la idea de un territorio funcional (como lo impulsaba el movimiento de quienes apoyaban el modelo metropolitano), ya que éste se basaba en la provisión de servicios y no como el generador de dichos servicios y actividades económicas.

Dado el contexto, el Modelo Metropolitano encuentra relevante el fortalecimiento de su idea de integración; así mismo, puntualiza que "el problema clave para su implementación era la fragmentación" (Lefèvre, 1998, p. 12). Con ello, se busca la reorganización institucional y su cobertura. Aunque esto no resulta suficiente: se aboga por el poder de disposición de los recursos financieros y autoridad sobre las redes técnicas (servicios), la distribución de las facultades y la autonomía de las autoridades para la toma de decisiones de acuerdo con las necesidades particulares de cada región, y la legitimidad política y administrativa a través del sufragio universal.

A partir de los nuevos arreglos institucionales propuestos por el modelo, se emplazan los supra municipales y los intra municipales, cada uno diferenciado por el grado de autoridad dentro de la estructura metropolitana. La supra municipalidad representa en el sentido más puro el modelo metropolitano, en tanto compila fielmente las características de poder, autonomía y legitimidad expuestas en el párrafo anterior. Por su parte, en "la intra-municipalidad, la legitimidad reposa sobre los miembros del gobierno y rara vez cuenta con autonomía sobre los recursos" (Lefèvre, 1998, p.13). Sobre estas dos modalidades, recaen los experimentos de go- biernos metropolitanos. Contradictoriamente, pese a que el ideal en el modelo metropolitano debería ser la adopción de la modalidad de supra municipalidad, en realidad, la modalidad intra municipal ha sido la de mayor implementación. Lefévre (1998), nos da los ejemplos de Metro Toronto (Canadá) y las "Communautés urbaines" (Francia). Entre tanto, el autor abre también el panorama, mostrando que en los Estados Unidos la Escuela de la Opción Pública ha sido más exitosa, al evidenciar grandes niveles de fragmentación institucional.

Existen elementos por los que el Modelo Metropolitano puede fallar: en ocasiones, la implementación puede ser llevada de manera autoritaria, lo que pone su legitimidad en una situación de desventaja, ya que ésta depende del reconocimiento y aceptación de las personas (Lefèvre, 1998, p. 15). Por otra parte, están los grupos de presión social, considerados otra escala de la estructura territorial, que pueden llegar a no aceptar la estructura funcional metropolitana.

Hacia la década de los noventa, el resurgimiento de los gobiernos metropolitanos reafirmó la caída del antiguo modelo metropolitano de entre los años sesenta y setenta, que se caracteriza por el reconocimiento de un sistema de actores más complejo, un gobierno que no goza de una suprema legitimidad y poder. "El gobierno es un igual a la sociedad" (Lefèvre, 1998, p. 18). Ello supone la constante negociación de ideas entre las autoridades locales (sector privado, asociaciones y grupos de interés y la población). Se deja atrás la descentralización que se venía dando en los años ochenta tras el abandono de reformas autoritarias, ahora reemplazada por la participación local voluntaria. En este sentido, el modelo institucional conformado a partir de la activa acción ciudadana se ve reflejada en las metas conjuntas y en la elaboración de consensos producto de la sinergia entre actores de base que, a su vez, se traduce en un mayor dinamismo social y movimiento de fuerzas endógenas. De acuerdo con 
Jouve y Lefèvre (1997), la institución aparece como un proceso a través de la implementación de políticas públicas que tienen un mayor impacto en la legitimidad de las decisiones de los grupos poblacionales más vulnerables.

En esencia, el ente rector en este nuevo modelo de gobiernos metropolitanos tiene la función de establecer prioridades dentro de la agenda pública (planes de desarrollo, planes estratégicos metropolitanos, programas administrativos, entre otros). Esto significa que "los intereses de cada actor pueden ser suplidos a cabalidad" (Lefèvre, 1998, p. 19). Así, el autor resalta que la legitimidad no depende solo de los arreglos institucionales, sin embargo, la aceptación generalizada ya la implica; además, destaca que dicha estructura está llamada a substituir las antiguas que entraban en un juego de choques de poder. Aunque resulte una visión más holística, el nuevo modelo de gobernanza está sujeto a los tradicionales problemas políticoinstitucionales y al 'clima económico actual'.

Para terminar, vale la pena hacer la reflexión de la internacional jerarquía que tiene hoy en día 'lo urbano' (Lefèvre, 1998, p. 22), sin olvidar los factores externos y periferias, que a fin de cuentas, son apoyo para el desarrollo de las metrópolis, en orden de localizarlas competitivamente en un mundo cada vez más globalizado. Para ello, mantener los valores de los territorios y sus procesos sociales, son la base de la consolidación de modelos sostenibles de gobernanza.

\section{Referencias}

Jouve, B. y Lefevre, C. (1997). When territorial political culture makes urban institution the metropolitan city of Bologna. Government and Policy, 15(1), 89-111. doi: 10.1068/c150089

Lefèvre, C. (1998). Metropolitan government and governance in western countries: A Critical Review. International Journal or Urban and Regional Research, 22, 9-25. doi: 10.1111/1468-2427.00120 

Su estructura básica se explica en 4 elementos (PILARES)

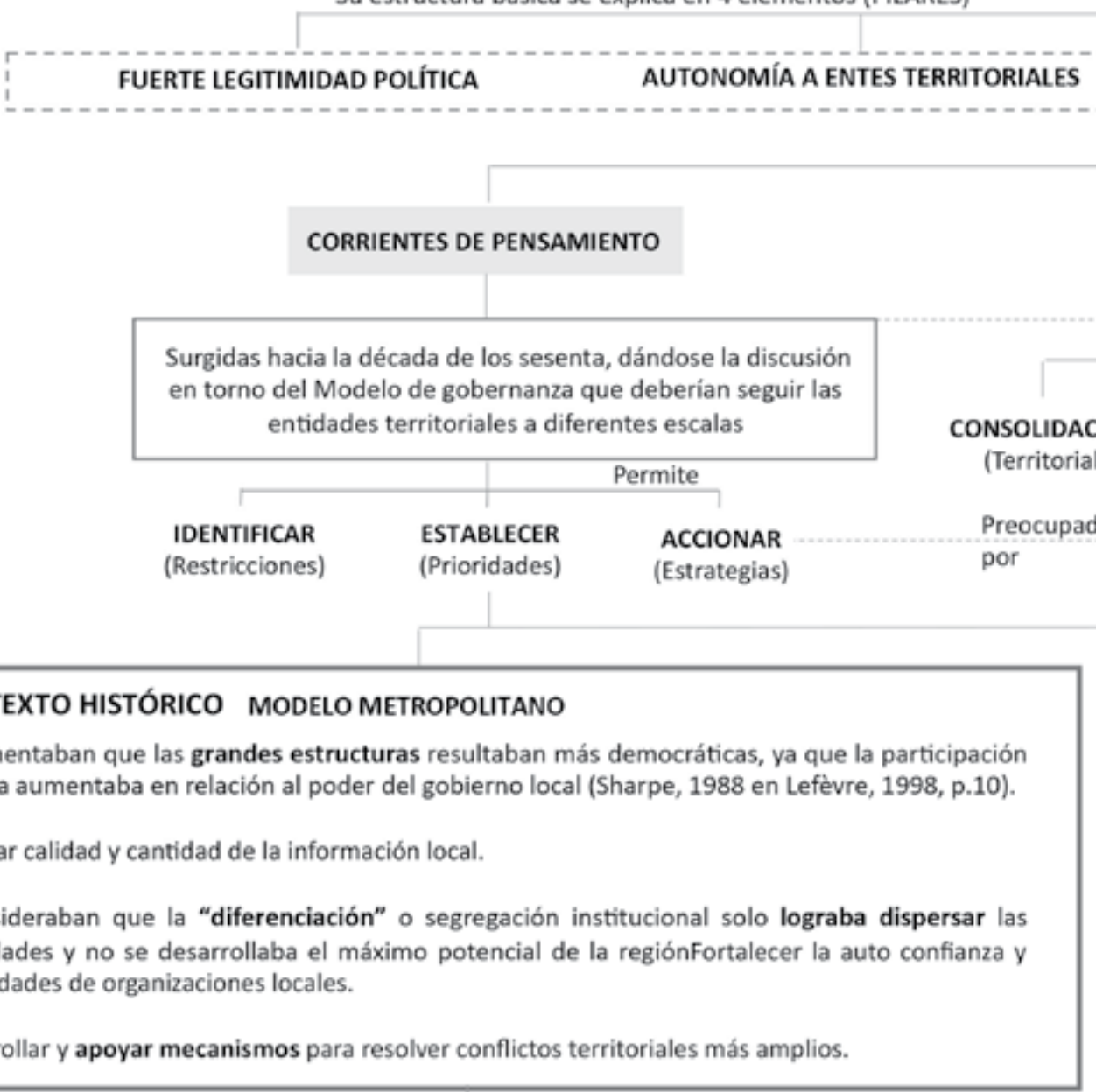

Las relaciones territoriales metropolitanas implican

Poder de disposición de
los recursos financieros
y autoridad sobre las
redes téc n ic as
(servicios).

\begin{tabular}{l} 
Autonomia de las \\
autoridades para la toma \\
de decisiones de acuerdo \\
a las necesidades \\
particulares de cada \\
región. \\
\hline
\end{tabular}

Legitimidad politica y
administrativa a
través del sufragio
universal.

Necesita generr Arreglos

Existen dos niveles de gobernanza a esta escala

Necesita generr Arre

\begin{tabular}{l} 
SUPRA MUNICPALIDAD \\
Compila fie Imente las \\
características de poder, \\
autonomía y legitimidad. \\
\hline
\end{tabular}

\begin{tabular}{|l|}
\hline INTRA MUNICPALIDAD \\
La legitimidad reposa sobre los \\
miembros del gobierno y no \\
cuenta con autonomía.
\end{tabular}

Puede haber problemas en s implementación

cuenta con autonomía.
○

\section{AMPLIO RANGO JURISDICCIONAL}

COBERTURA TERRITORIAL

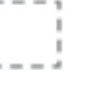


